\title{
Effect of Nonlinear Thermal Radiation on Boundary Layer Flow of Viscous Fluid over Nonlinear Stretching Sheet with Injection/Suction
}

\author{
T. Vijaya Laxmi ${ }^{1,2 *}$, Bandari Shankar1 \\ ${ }^{1}$ Department of Mathematics, Osmania University, Hyderabad, India \\ ${ }^{2}$ Department of Mathematics, M.V.S. Govt. Arts \& Science College, Mahabubnagar, India \\ Email: *vijaya9966998024@rediffmail.com, bandarishankar@gmail.co.in
}

Received 7 January 2016; accepted 22 February 2016; published 25 February 2016

Copyright (C) 2016 by authors and Scientific Research Publishing Inc.

This work is licensed under the Creative Commons Attribution International License (CC BY).

http://creativecommons.org/licenses/by/4.0/

(c) (i) Open Access

\section{Abstract}

The present study reveals the effect of nonlinear thermal radiation and magnetic field on a boundary layer flow of a viscous fluid over a nonlinear stretching sheet with suction or an injection. Using suitable similarity transformations, governing partial differential equations were reduced to higher order ordinary differential equations and further these are solved numerically using of Keller-Box method. Effect of flow controlling parameter on velocity, temperature and nanoparticle fluid concentration, local skin friction coefficient, local Nusselt number and local Sherwood numbers are discussed. It is found that the dimensionless velocity decreases and temperature, concentration are increased with the increasing of magnetic parameter. The temperature profile is an increasing function of thermal radiation when it is increasing.

\section{Keywords}

Nonlinear Thermal Radiation, Stretching Sheet, Boundary Layer, Keller-Box Method, Suction/Injection

\section{Introduction}

Boundary layer behaviour with the heat and mass transfer over a nonlinear stretching sheet in the presence of

${ }^{*}$ Corresponding author.

How to cite this paper: Laxmi, T.V. and Shankar, B. (2016) Effect of Nonlinear Thermal Radiation on Boundary Layer Flow of Viscous Fluid over Nonlinear Stretching Sheet with Injection/Suction. Journal of Applied Mathematics and Physics, 4, 307319. http://dx.doi.org/10.4236/jamp.2016.42038 
thermal radiation is very important for various engineering and industrial applications. These applications involve the cooling of continuous strips or filaments by drawing them through a quiescent fluid. Flow past a stretching surface with different stretching velocity has been addressed previously. Grubka et al. [1] studied the effect of heat transfer characteristics of a boundary layer flow of fluids flow over a linear continuous stretching surface. Chen et al. [2] studied the heat transfer effect of a boundary layer flow over a linear stretching sheet which was subjected to suction/blowing in the present of the sheet with prescribed wall temperature and heat flux. Kumaran and his group [3] examined the transition effect of boundary layer flow due to a presence and an absence of magnetic field over a viscous flow past a stretching sheet and analyzed the task numerically by implicit finite difference technique (Crank-Nicholson method). Bakar et al. [4] investigated the steady laminar flow over a stretching sheet with a convective boundary condition by the considering of the effect of partial slip. Krishnamurthy et al. [5] investigated the effect of viscous dissipation on hydromagnetic fluid flow and heat transfer of nanofluid over an exponentially stretching sheet with fluid-particle suspension. However, studies on heat and mass, transfer in the laminar boundary layer flow over a non-linear stretching sheet is very less. It is well known to the all research community that the stretching is not necessarily linear in many industrial applications. Many authors analysed flow, heat and mass transfer transport of both Netonian and non-Newtonian fluid over nonlinear stretching surfaces. Rana and Bhargava [6] numerically investigated, steady, laminar boundary fluid flow which results from the non-linear stretching of a flat surface in a nanofluid. Khan et al. [7] studied three-dimensional flow of nanofluid over an elastic sheet stretched non-linearly in two lateral directions and the results of their study reveal that penetration depths of temperature and nanoparticle volume fraction are decreasing functions of the power-law index. Pal and Mandal [8] obtained numerical solution by fifth-order Runge-Kutta-Fehlberg method with shooting technique for magnetohydrodynamic boundary layer flow of an electrically conducting convective nanofluids induced by a non-linear vertical stretching/shrinking sheet with viscous dissipation, thermal radiation, and Ohmic heating. Mabood et al. [9] obtained numerical results for MHD laminar boundary layer flow with heat and mass transfer of an electrically conducting water-based nanofluid over a nonlinear stretching sheet with viscous dissipation effect. Das [10] performed a numerical investigation, to study the problem of boundary layer flow of a nanofluid over non-linear permeable stretching sheet at prescribed surface temperature in the presence of partial slip.

Heat transfer, influenced by thermal radiation has applications in many technological processes, including nuclear power plants, gas turbines and the various propulsion devices for aircraft, missiles, satellites and space vehicles. But a linear radiation is not valid for high temperature difference and also dimensionless parameter that is used in the linearized Rosseland approximation is only the effective Prandtl number [11], Pntokratoras [12] investigated the effect of linear or non-linear Rosseland radiation on steady laminar natural convection along a vertical isothermal plate by using a new radiation parameter called film radiation parameter. Hayat et al. [13] analysed the effect of nonlinear thermal radiation and constant applied magnetic field on magnetohydrodynamic three-dimensional flow of couple stress nanofluid and viscous nanofluid in the presence of thermophoresis and Brownian motion effects. Shehzad et al. [14] have explored the characteristics of thermophoresis and Brownian motion in magnetohydrodynamic three-dimensional flow of nano Jeffrey fluid in the presence of nonlinear thermal radiation.

Another important aspect, which influences heat transfer processes is effects of injection or suction. It is wellknown that the effects of injection on the boundary layer flow are of interest in reducing the drag force. Many of the authors have studied heat transfer by considering an uniform and non-uniform heat source/sink effects, which are crucial in controlling the heat transfer. Jalilpour et al. [15] presented a theoretical study to analyze the effect of heat generation/absorption on magnetohydrodynamic stagnation point flow and heat transfer over a porous stretching surface, with prescribed surface heat flux. Cao et al. [16] have investigated the magnetohydrodynamic (MHD) Maxwell fluid past a stretching plate with suction/injection in the presence of nanoparticles. By considering investigates steady laminar boundary layer flow of power law fluids past a flat surface with suction or injection and magnetic effects Lin et al. [17] investigates steady laminar boundary layer flow of power law fluids past a flat surface with suction or injection and magnetic effects.

The main aim of the present paper is to solve the problem of magnetohydrodynamics (MHD) studies on boundary layer flow over nonlinear stretching sheet with injection/suction and nonlinear thermal radiation of a viscous fluid by adopting the well known Keller-Box method. I have verified the obtained numerical results with earlier work and a very good agreement has been established. 


\section{Formulation of the Problem}

Consider a two dimensional steady laminar boundary layer flow over a permeable nonlinear stretching sheet in the presence of applied magnetic in an incompressible viscous fluid. Presume sheet direction is horizontal with the $x$-axis and $y$-axis is the direction normal to the stretching sheet. Present flow is restricted to $y>0$ and is due to the simultaneous effect of two equal and opposite forces along the direction of the $x$-axis and maintained the origin is fixed. The sheet coincides with the plane $y=0$ and its velocity is assumed as $u_{w}(x)=a x^{n}$, where " $a$ " and " $n$ " are positive constant values. The flow configuration is given in Figure 1. The boundary layer equations, under the Boussinesq approximations and for steady state flow conditions are given by:

$$
\begin{gathered}
\frac{\partial u}{\partial x}+\frac{\partial v}{\partial y}=0 \\
u \frac{\partial u}{\partial x}+v \frac{\partial u}{\partial y}=v \frac{\partial^{2} u}{\partial y^{2}}-\frac{\sigma}{\rho} B_{0}^{2}(x) u \\
u \frac{\partial T}{\partial x}+v \frac{\partial T}{\partial y}=\alpha \frac{\partial^{2} T}{\partial y^{2}}-\frac{1}{\rho c_{p}} \frac{\partial q_{r}}{\partial y} \\
u \frac{\partial C}{\partial x}+v \frac{\partial C}{\partial y}=D \frac{\partial^{2} C}{\partial y^{2}}
\end{gathered}
$$

We assume that the variable magnetic field $B(x)$ and is of the form $B(x)=B_{0} x^{\frac{n-1}{2}}$ [18]-[20]. The boundary conditions for velocity, temperature and concentration are considered are

$$
\begin{aligned}
& u=U_{w}(x)=a x^{n}, v=v_{w}(x), T=T_{w}, C=C_{w} \text { at } y=0 \\
& \text { and } u \rightarrow 0, T \rightarrow T_{\infty}, C \rightarrow C_{\infty} \text { as } y \rightarrow \infty
\end{aligned}
$$

Unlike the linearized Rosseland approximation, we use nonlinear Rosseland diffusion approximation from which one can obtain results for both small and large differences between $T_{w}$ and $T_{\infty}$.

Using Rosseland (Rosseland, 1931) approximation for radiation, the radiative heat flux is simplified as,

$$
q_{r}=-\frac{4 \sigma^{*}}{3 k^{*}} \frac{\partial T^{4}}{\partial y},
$$

where $\sigma^{*}$ and $k^{*}$ are the Stefan-Boltzmann constant and mean absorption coefficient respectively and where $T$ is the temperature across the boundary layer.

For a boundary layer flow over a horizontal flat plate, from Equation (2.6) we get,

$$
q_{r}=\left(-\frac{16 \sigma^{*} T^{3}}{3 k^{*}}\right) \frac{\mathrm{d} T}{\mathrm{~d} y}
$$

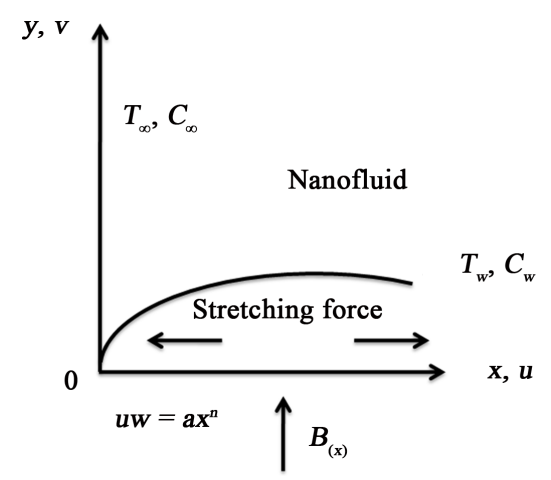

Figure 1. Flow organization with coordinate system. 
In view to Equation (6), energy Equation (3) takes the form

$$
u \frac{\partial T}{\partial x}+v \frac{\partial T}{\partial y}=\frac{\partial}{\partial y}\left[\left(\alpha+\frac{16 \sigma^{*} T^{3}}{3 k^{*} \rho c_{p}}\right) \frac{\partial T}{\partial y}\right]
$$

where $\alpha=\frac{k}{\rho c}, k$ being the thermal conductivity.

The following shifts are used to transform the governing partial differential equations into a scheme of ordinary differential equations.

$$
\begin{aligned}
& \eta=y\left(\frac{a(n+1)}{2 v}\right)^{\frac{1}{2}} x^{\frac{n-1}{2}} ; f^{\prime}=F ; \varphi(x, y)=\left(\frac{2 a v}{n+1} x^{n+1}\right)^{\frac{1}{2}} f(\eta) ; v=-\frac{\partial \varphi}{\partial x} \\
& u=\frac{\partial \varphi}{\partial y} ; H(\eta)=\frac{C-C_{\infty}}{C_{w}-C_{\infty}} ; u=a x^{n} f^{\prime} ; v=-\sqrt{\frac{a v(n+1)}{2}} x^{\frac{n-1}{2}}\left(f+\eta\left(\frac{n-1}{n+1}\right) f^{\prime}\right) \\
& P_{r}=\frac{v}{\alpha} ; \quad S_{c}=\frac{v}{D} \\
& T=T_{\infty}\left(1+\left(\theta_{w}-1\right) G(\eta)\right)
\end{aligned}
$$

where $\theta_{w}=\frac{T_{w}}{T_{\infty}}$, the temperature ratio parameter.

The similarity variable $\eta$ and dimensionless stream function $\psi$ satisfy the continuity equation. With the similarity variable $\eta$, the Equations (2), (4) and (8) reduces to the following ordinary differential equations, respectively

$$
\begin{gathered}
f^{\prime \prime \prime}+f f^{\prime \prime}-\frac{2 n}{n+1} f^{\prime 2}-M f^{\prime}=0 \\
3 R d\left(1+\left(\theta_{w}-1\right) G\right)^{2}\left(\theta_{w}-1\right) G^{\prime 2}+\left(1+R d\left(1+\left(\theta_{w}-1\right) \theta\right)^{3}\right) G^{\prime \prime}+P_{r} f G^{\prime}=0 \\
H^{\prime \prime}+S_{C} f H^{\prime}=0
\end{gathered}
$$

Using the similarity transformation and the boundary conditions which are mentioned in equation (5), the transformed boundary conditions are;

$$
\begin{aligned}
& f(0)=s, f^{\prime}(0)=1, G(0)=1, H(0)=1 \text { at } \eta=0 \\
& f^{\prime} \rightarrow 0, G \rightarrow 0, H \rightarrow 0 \text { as } \eta \rightarrow \infty
\end{aligned}
$$

Here $s=-\frac{v_{w}(x)}{\sqrt{a v \frac{n+1}{2} x^{n-1}}}$ is the suction/injection parameter and $s<0, s>0 \& s=0$ belongs to injection, suction and impermeability cases respectively. Magnetic parameter of $M=\frac{2 \sigma B^{2}}{a \rho(n+1)}$. The physical quantities of importance from the engineering point of observation are the skin friction coefficient, the local Nusselt number $\left(N v_{x}\right)$ and the local Sherwood number $\left(S h_{x}\right)$ which are defined as

$$
\begin{gathered}
C_{f}=\frac{2 \tau_{w}}{\left(\rho u^{2} w\right)} \\
N u_{x}=\frac{x q_{w}}{k\left(T_{w}-T_{\infty}\right)} \\
S h_{x}=\frac{x q_{m}}{D\left(C_{w}-C_{\infty}\right)}
\end{gathered}
$$


Here the wall heat flux $q_{w}$ and the mass flux $q_{m}$ are given as:

$$
\tau_{w}=\mu\left(\frac{\partial u}{\partial y}\right)_{y=0}, \quad q_{w}=-k\left(\frac{\partial T}{\partial y}\right)_{y=0}+\left(q_{r}\right)_{w}, \quad q_{m}=-D\left(\frac{\partial C}{\partial y}\right)_{y=0}
$$

Using of similarity variable, the Equations (13), (14) and (15) becomes:

$$
\begin{gathered}
f^{\prime \prime}(0)=c_{f}\left(\sqrt{R e_{x} / 2(n+1)}\right) \\
-G(0)=\frac{N u_{x}}{\left(1+R d \theta_{w}^{3}\right) \sqrt{\frac{R e_{x}(n+1)}{2}}} \\
-H(0)=\frac{S h_{x}}{\sqrt{\frac{R e_{x}(n+1)}{2}}}
\end{gathered}
$$

Here $R e=\frac{u_{w} X}{v}$ is the Reynolds number.

\section{Numerical Procedure}

The ordinary differential Equations (9), (10), (11) with the boundary conditions (12) are solved numerically by using of Keller-Box method with MATLAB, as revealed by (19), the following few steps are involved to achieve Numerical solutions:

- Reduce the above mentioned higher order ordinary differential equations into a system of first order ordinary differential equations;

- Write the finite differences for the first order equations.

- Linearize the algebraic equations by Newton's method, and write them in matrix-vector form; and

- Solve the linear system by the block tri-diagonal elimination technique.

- To get the accuracy of this method the appropriate initial guesses have been chosen. The following initial guesses are chosen.

- $f_{0}(\eta)=1+s-\mathrm{e}^{-\eta}, G_{0}(\eta)=\mathrm{e}^{-\eta}, H_{0}(\eta)=\mathrm{e}^{-\eta}$.

\section{Results and Discussion}

To have a check on the accuracy of the numerical procedure used, first test computations for $\theta^{\prime}(0)$ are carried out for viscous fluid for various values of $P_{r}$ and compared with the available published results of Goyal and Bhargava (2014), Gorla and Sidawi (1994) and Nadeem and Hussain (2013) in Table 1 and they are found to be in excellent agreement. The parameters for the present study are magnetic parameter $M$, Prandtl number $\left(P_{r}\right)$, Schmidt number $\left(S_{c}\right)$, suction/injection parameter $s$ radiation parameter $(R d)$, and the nonlinear stretching sheet parameter $(\eta)$.

\begin{tabular}{ccccc}
\multicolumn{7}{l}{ Table 1. Comparison table for viscous case $-\theta^{\prime}(0)$ for $k_{p}=A=B=\beta=0, N r=10^{-6}, L e=10}$. \\
\hline$P r$ & $\begin{array}{c}\text { Nadeem and Hussain } \\
\text { (HAM method) (2013) }\end{array}$ & Gorla and Sidawi (1994) & $\begin{array}{c}\text { Goyal and Bhargava } \\
\text { (FEM Method) (2014) }\end{array}$ & $\begin{array}{c}\text { Present } \\
\text { (RKF45 Method) }\end{array}$ \\
\hline 0.2 & 0.169 & 0.1691 & 0.1691 & 0.170259788 \\
0.7 & 0.454 & 0.5349 & 0.4539 & 0.454447258 \\
2 & 0.911 & 0.9114 & 0.9113 & 0.911352755 \\
7 & & 1.8905 & 1.8954 & 1.895400395 \\
20 & & 3.3539 & 3.3539 & 3.353901838 \\
\hline
\end{tabular}


A parametric study is carried out to demonstrate the effects of governing parameters on velocity, temperature and concentration profiles. Figure 2 and Figure 3 illustrate the effect of magnetic and nonlinear stretching parameters on the dimensionless velocity. It is evidently observed that the velocity profile of the viscous fluid is insignificantly reduced with increasing values of $M$ and $\eta$. The velocity is reduced strongly as the results of increased magnetic field, and is due to the fact that the magnetic field commences a retarding body force which will acts transverse to the direction of the functional magnetic field, and is well known as Lorentz force, which will decelerate the boundary layer flow and the thickness of the momentum boundary layer. Hence, this will encourage an increase of the velocity gradient at its surface as clearly expressed in figures.

Impact of Prandtl number on the temperature profile is given in Figure 4, and it indicates that increasing the Prandtl number decrease the temperature profile. A similar conclusion can be drawn to the effect of Schmidt number $\left(S_{c}\right)$ on the species concentration in the presence of magnetic field as it is indicated in the Figure 5. Figure 6 and Figure 7 respectively shows the effect of thermal radiation parameter $(R d)$ and temperature ratio parameter $\left(\theta_{w}\right)$ on temperature profiles. It is observed that, the temperature profile increases for increasing values of $\theta_{w}$. Further it shows that, the temperature profiles increase with increase in $R d$. This is because, in-

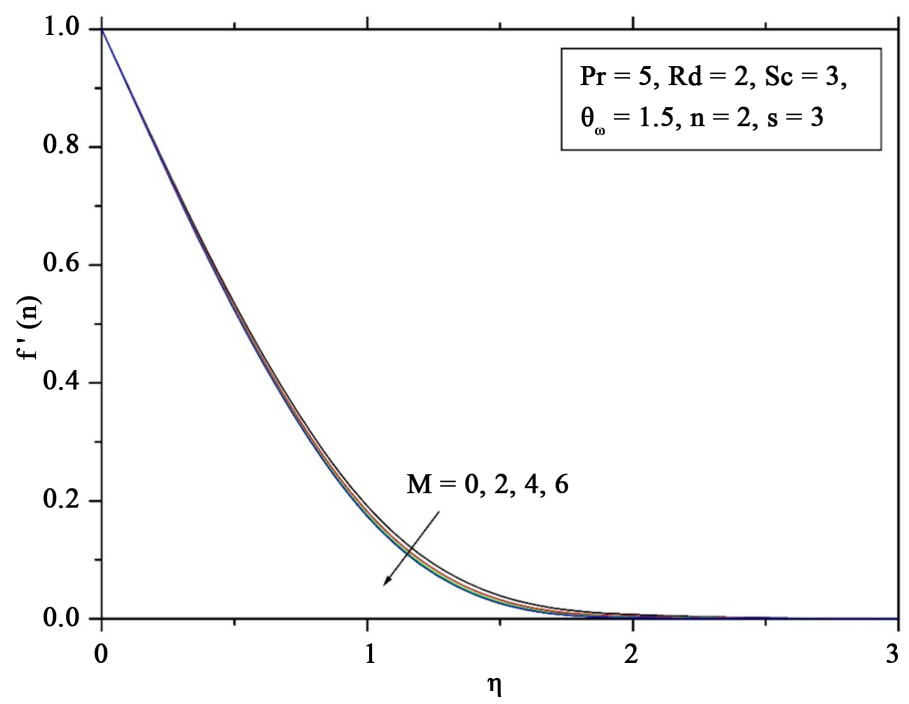

Figure 2. Effect of $M$ on velocity profile.

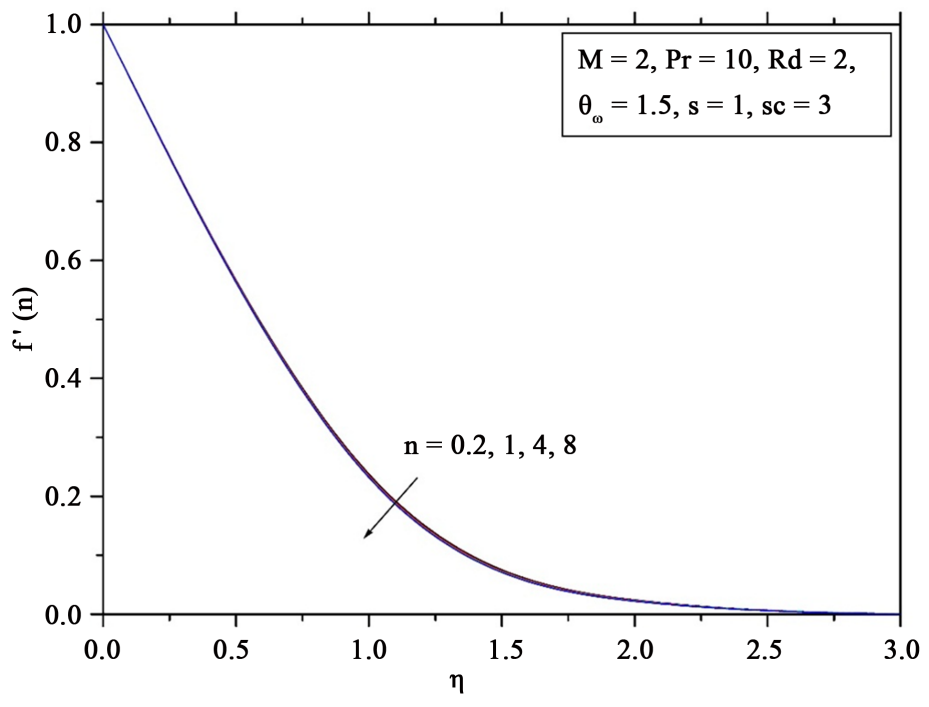

Figure 3. Effect of stretching sheet parameter $\eta$ on velocity profile. 


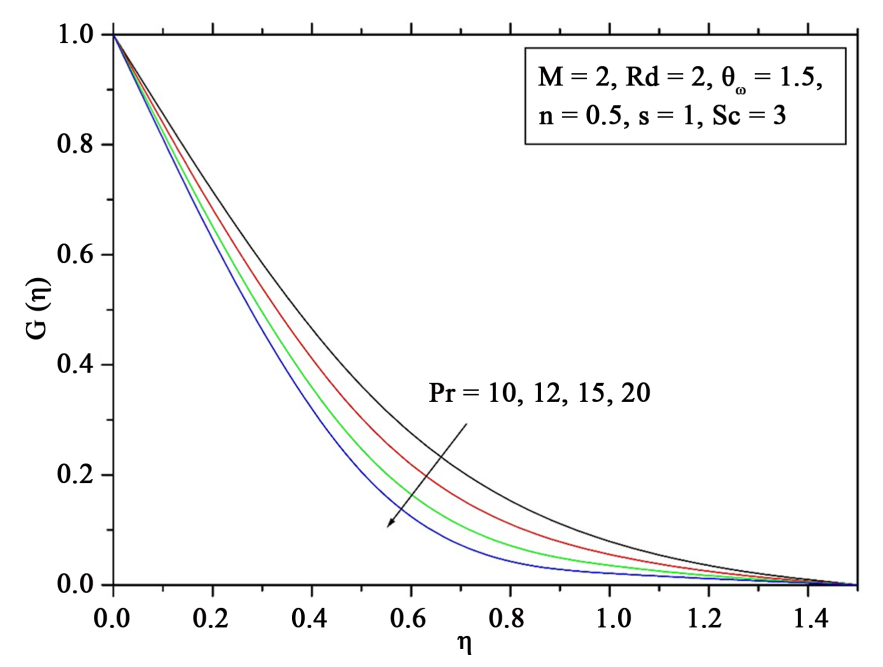

Figure 4. Effect of $P_{r}$ on temperature profile.

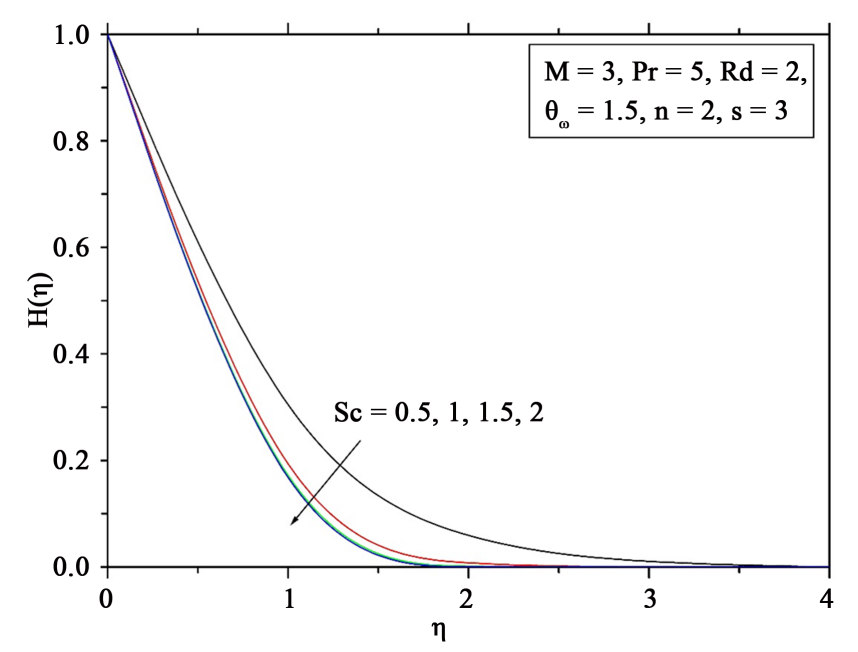

Figure 5. Effect of Sc on concentration profile.

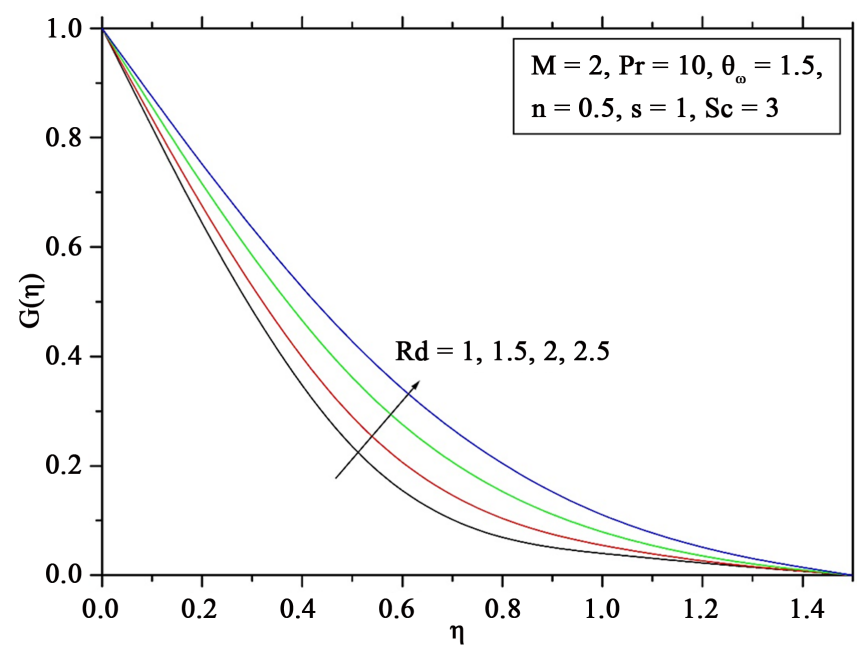

Figure 6. Effect of $R d \quad$ on temperature profile. 


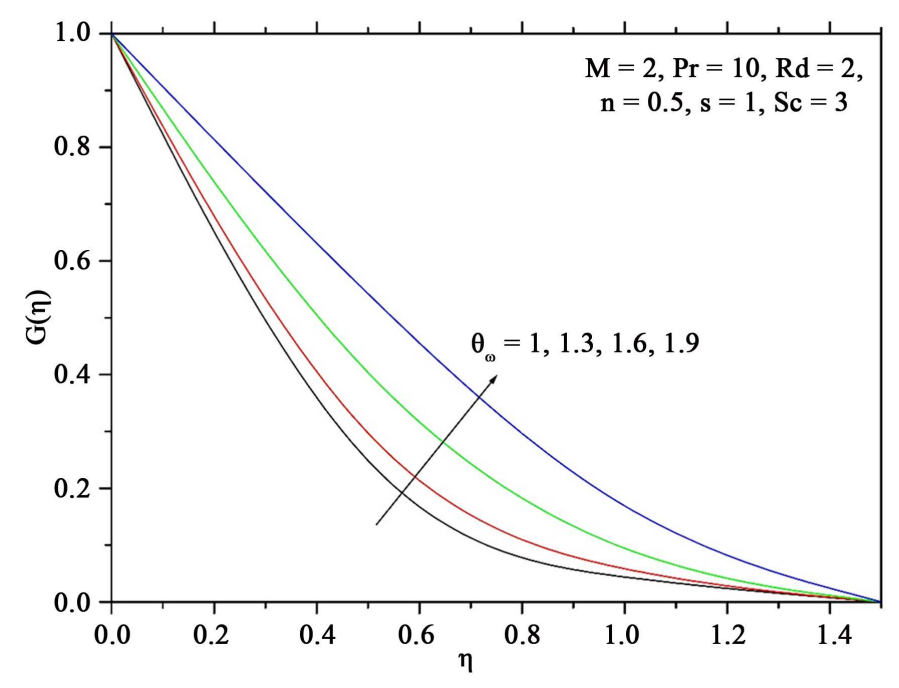

Figure 7. Effect of $\theta_{w}$ on temperature profile.

crease in the radiation parameter provides more heat to fluid that cause an enhancement in the temperature and thermal boundary layer thickness. Figures 8-10 depicts the effect the suction/injection parameter $s$ on velocity, temperature and concentration profiles, respectively. These plots shows that velocity decreases significantly with increasing suction parameter whereas fluid velocity is found to increase with injection and temperature decreases with increasing suction parameter whereas it increases due to blowing.

Now, we focus on the variations of quantities of the physical interest from an engineering point of view. That is, local skin friction $\left(C f_{x}\right)$, the local Nusselt number $\left(N u_{x}\right)$ and the local Sherwood number $\left(S h_{x}\right)$. Figure 11 indicates of that for the larger values of magnetic parameter $M$, the skin friction coefficient shows the increasing behaviour correspond to the raise in the values of nonlinear stretching parameter $\eta$. This means fluid motion on the wall of the sheet is accelerated when we strengthen the effect of parameters.

Figure 12 depicts the variation of heat transfer rate with the magnetic field at different Prandtl number. It is experimental that the Nusselt numbers decrease with the increase in magnetic parameter and Prandtl number values. Figure 13 and Figure 14 illustrates the effect of $\theta_{w}, \eta$ and $R d$ on coefficient of local Nusselt number. It is observed that heat transfer rate decreases with $\theta_{w}$ and $R d$ but increases with $\eta$.

The numerical values of skin friction, Nusselt number and Sherwood number for various flow controlling parameters are tabulated in Table 2. It clear from the Table 2, that the Nusselt number and Sherwood numbers are decreases and Skin friction coefficient is increases for increasing values of $M$. We can also observe that in the case of suction the skin friction, Nusselt number and Sherwood number are higher than that in the case of injection.

\section{Conclusions}

MHD boundary layer and heat transfer of a viscous fluid over a nonlinear stretching sheet in the presence of nonlinear thermal radiation with suction/injection have been studied in the current paper. A similarity solution is presented to analyse the effect of Prandtl number, magnetic parameter, nonlinearlity of stretching sheet and nonlinear thermal radiation, Schmidt number, and suction/injection parameters on velocity, temperature and concentration profiles. The effects of skin friction coefficient and surface heat and mass transfer characteristics are discussed graphically and also numerically. The main observations of the present study are as follows:

- The velocity profile of the viscous fluid is insignificantly reduced with increasing values of magnetic and nonlinearity parameters.

- Rising of Prandtl number resulted in decreases the temperature of the fluid.

- As Schmidt number increases the species concentration decreases.

- Increasing the suction/injection parameter reduces the velocity profiles.

- Increase of nonlinear stretching sheet parameter, magnetic field results in diminishing of skin friction coefficient. 


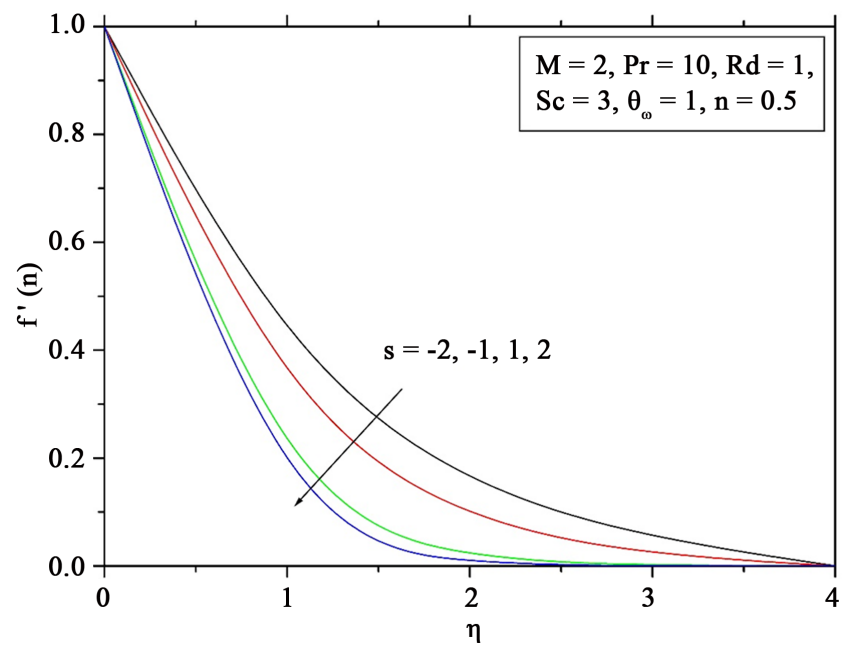

Figure 8. Effect of suction/injection parameter $s$ on velocity profile.

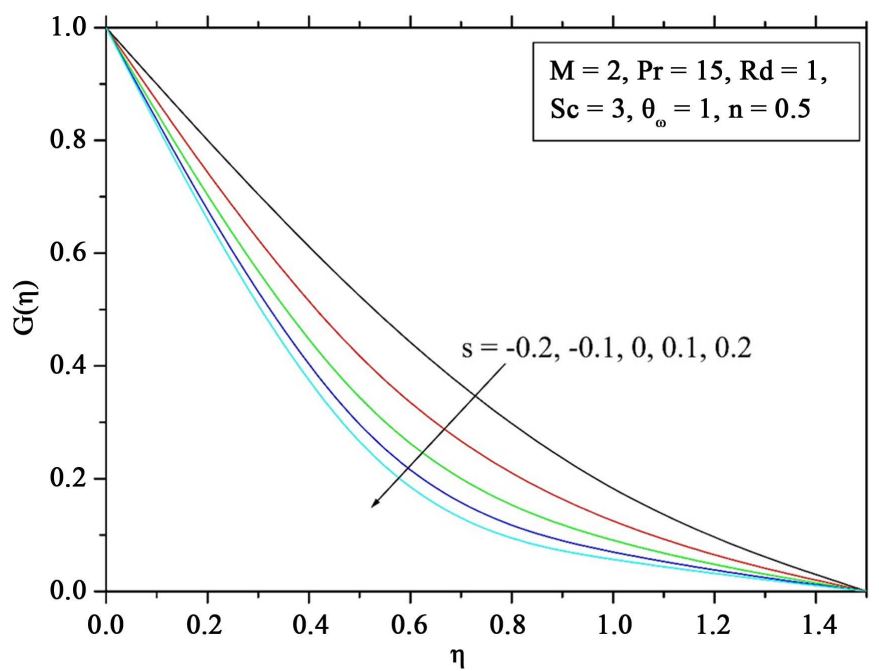

Figure 9. Effect of suction/injection parameter $s$ on temperature profile.

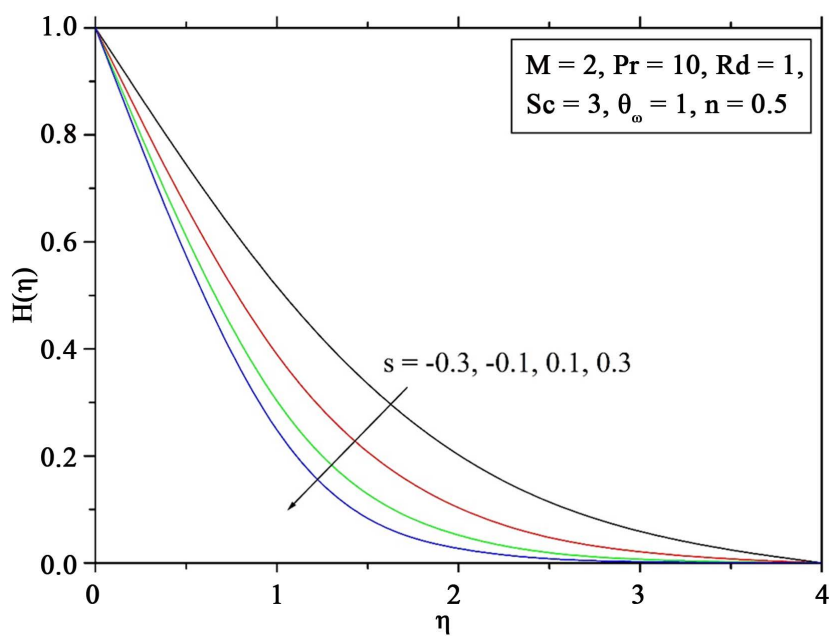

Figure 10. Effect of suction/injection parameters on concentration profile. 


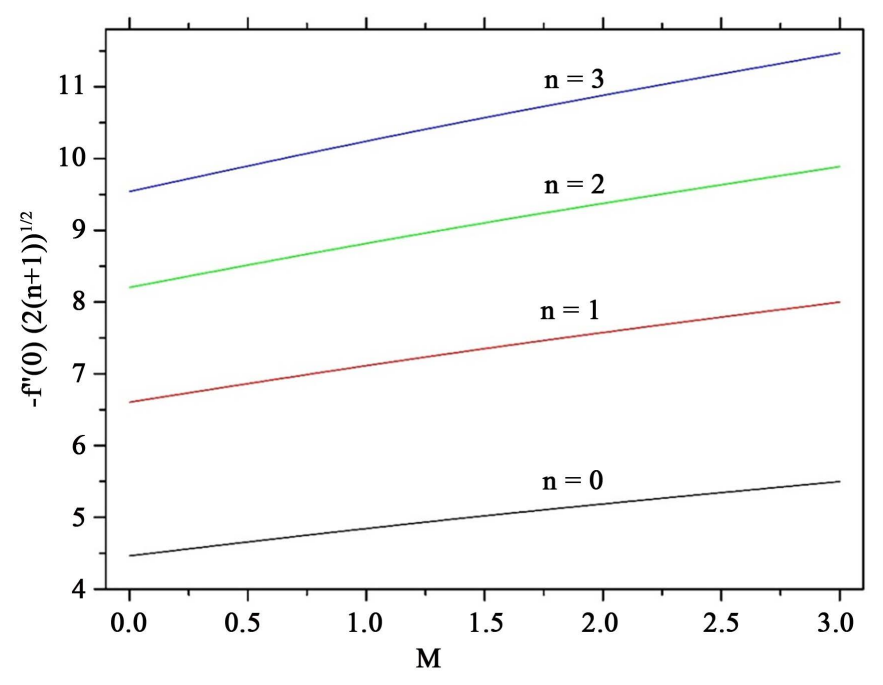

Figure 11. Effect of $M$ and $n$ on skin friction coefficient.

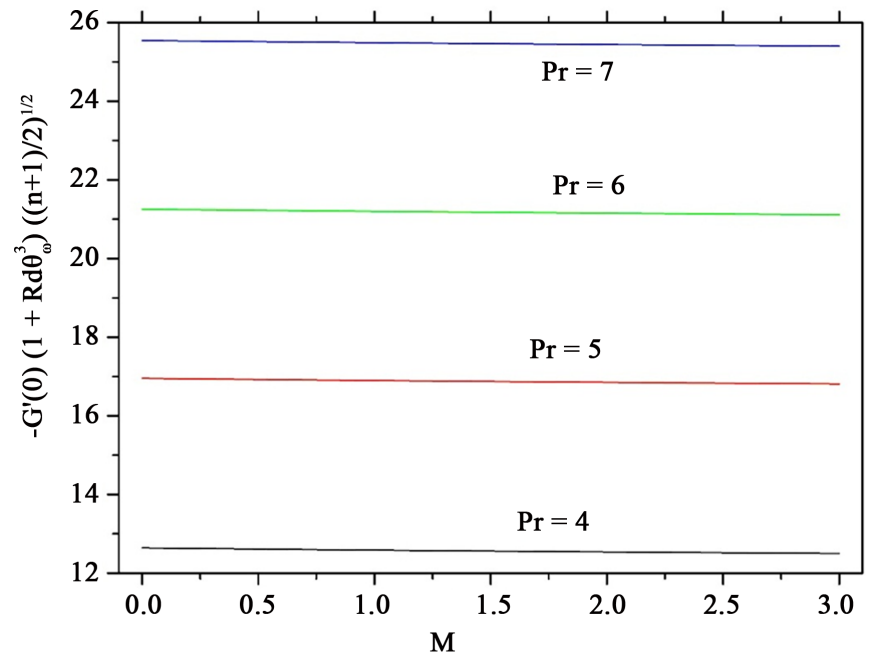

Figure 12. Variation of heat transfer rate with $M$ and $P_{r}$.

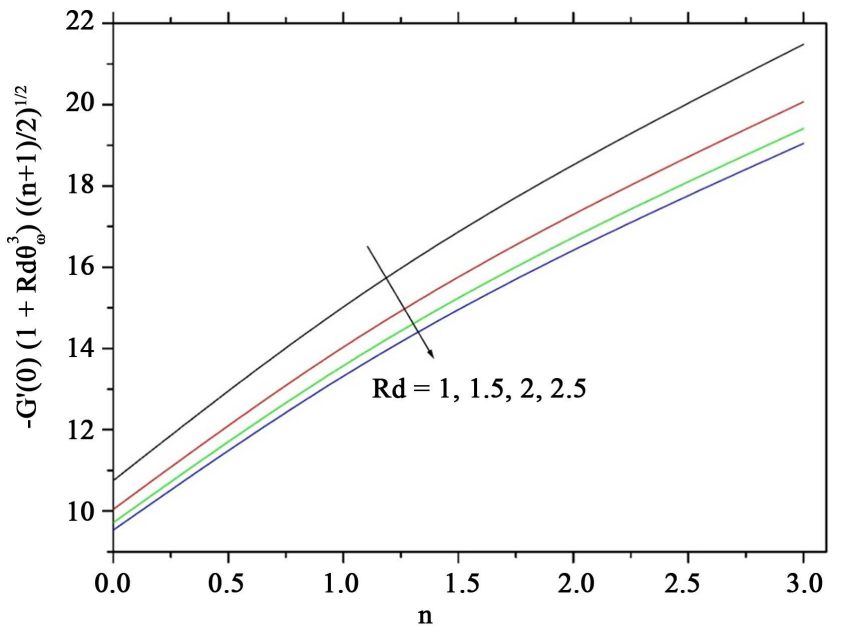

Figure 13. Variation of heat transfer rate with $n$ and $R d$. 


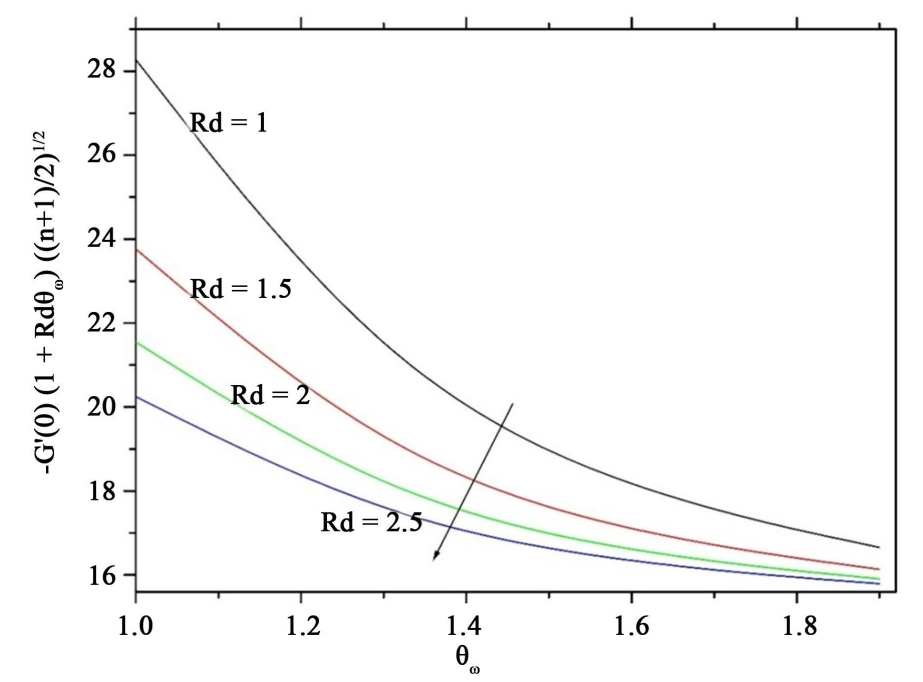

Figure 14. Variation of heat transfer rate with $\theta_{w}$ and $R d$.

Table 2. Values of skin friction coefficient, Nusselt number and Sherwood number for different values of parameters when $\theta_{w}=1.2, S e=4, \operatorname{Pr}=6$.

\begin{tabular}{|c|c|c|c|c|c|}
\hline$M$ & $\eta$ & s & $-f^{\prime \prime}(0) \sqrt{2(n+1)}$ & $-G^{\prime}(0)\left(1+R d \theta_{w}^{3} \sqrt{\frac{n+1}{2}}\right.$ & $-H^{\prime}(0) \sqrt{\frac{n+1}{2}}$ \\
\hline 1 & & & 8.828382 & 16.89666 & 11.30631 \\
\hline 2 & & & 9.382812 & 16.84966 & 11.30162 \\
\hline 3 & & & 9.887555 & 16.80994 & 11.29749 \\
\hline \multirow[t]{6}{*}{3} & 1 & & 8.00 & 13.72852 & 9.224813 \\
\hline & 2 & & 9.887555 & 7.318164 & 11.29749 \\
\hline & 3 & & 11.46847 & 19.40817 & 13.0449 \\
\hline & 2 & 2 & 8.030919 & 10.26802 & 7.726226 \\
\hline & & 3 & 9.887555 & 16.80994 & 11.29749 \\
\hline & & 4 & 11.90432 & 23.54166 & 14.91149 \\
\hline
\end{tabular}

\section{Acknowledgements}

The author T. Vijayalaxmi grateful to University Grants Commission (UGC), India for awarding Faculty Development Programme (FDP) and also thankful to CCE, Govt. of Telangana State and Principal, M.V.S. Govt. Arts \& Science College, Mahabubnagar, Telangana State.

\section{References}

[1] Grubka, L.G. and Bobba, K.M. (1985) Heat Transfer Characteristics of a Continuous, Stretching Surface with Variable Temperature. ASME Journal of Heat Transfer, 107, 248-250. http://dx.doi.org/10.1115/1.3247387

[2] Chen, C.K. and Char, M.I. (1988) Heat Transfer of a Continuous, Stretching Surface with Suction or Blowing. Journal of Mathematical Analysis and Applications, 135, 568-580. http://dx.doi.org/10.1016/0022-247X(88)90172-2

[3] Kumaran, V., Kumar, A.V. and Pop, I. (2010) Transition of MHD Boundary Layer Flow past a Stretching Sheet. Communications in Nonlinear Science and Numerical Simulation, 15, 300-311. http://dx.doi.org/10.1016/j.cnsns.2009.03.027

[4] Bakar, N., Zaimi, W., Hamid, R., Bidin, B. and Ishak, A. (2012) Boundary Layer Flow over a Stretching Sheet with a 
Convective Boundary Condition and Slip Effect. World Applied Sciences Journal, 17, 49-53.

[5] Krishnamurthy, M.R., Prasanna Kumara, B.C., Gireesha, B.J. and Rama Subba Reddy, G. (2015) Effect of Chemical Reaction on MHD Boundary Layer Flow and Melting Heat Transfer of Williamson Nanofluid in Porous Medium. Engineering Science and Technology.

[6] Rana, P. and Bhargava, R. (2012) Flow and Heat Transfer of a Nanofluid over a Nonlinearly Stretching Sheet: A Numerical Study. Communications in Nonlinear Science and Numerical Simulation, 17, 212-226. http://dx.doi.org/10.1016/j.cnsns.2011.05.009

[7] Ahmad Khan, J., Mustafa, M., Hayat, T. and Alsaedi, A. (2015) Three-Dimensional Flow of Nanofluid over a NonLinearly Stretching Sheet: An Application to Solar Energy. International Journal of Heat and Mass Transfer, 86, 158164. http://dx.doi.org/10.1016/j.ijheatmasstransfer.2015.02.078

[8] Pal, D. and Mandal, G. (2015) Hydromagnetic Convective-Radiative Boundary Layer Flow of Nanofluids Induced by a Non-Linear Vertical Stretching/Shrinking Sheet with Viscous-Ohmic Dissipation. Powder Technology, 279, 61-74. http://dx.doi.org/10.1016/j.powtec.2015.03.043

[9] Mabood, F., Khan, W.A. and Ismail, A.I.M. (2015) MHD Boundary Layer Flow and Heat Transfer of Nanofluids over a Nonlinear Stretching Sheet: A Numerical Study. Journal of Magnetism and Magnetic Materials, 374, 569-576. http://dx.doi.org/10.1016/j.jmmm.2014.09.013

[10] Das, K. (2015) Nanofluid Flow over a Non-Linear Permeable Stretching Sheet with Partial Slip. Journal of the Egyptian Mathematical Society, 23, 451-456. http://dx.doi.org/10.1016/j.joems.2014.06.014

[11] Magyari, E. and Pantokratoras, A. (2011) Note on the Effect of Thermal Radiation in the Linearized Rosseland Approximation on the Heat Transfer Characteristics of Various Boundary Layer Flows. International Communications in Heat and Mass Transfer, 38, 554-556. http://dx.doi.org/10.1016/j.icheatmasstransfer.2011.03.006

[12] Pantokratoras, A. (2014) Natural Convection along a Vertical Isothermal Plate with Linear and Non-Linear Rosseland Thermal Radiation. International Journal of Thermal Sciences, 84, 151-157. http://dx.doi.org/10.1016/j.ijthermalsci.2014.05.015

[13] Hayat, T., Muhammad, T., Alsaedi, A. and Alhuthali, M.S. (2015) Magnetohydrodynamic Three-Dimensional Flow of Viscoelastic Nanofluid in the Presence of Nonlinear Thermal Radiation. Journal of Magnetism and Magnetic Materials, 385, 222-229. http://dx.doi.org/10.1016/j.jmmm.2015.02.046

[14] Shehzad, S.A., Hayat, T., Alsaedi, A. and Obid, M. A. (2014) Nonlinear Thermal Radiation in Three-Dimensional Flow of Jeffrey Nanofluid: A Model for Solar Energy. Applied Mathematics and Computation, 248, 273-286. http://dx.doi.org/10.1016/j.amc.2014.09.091

[15] Jalilpour, B., Jafarmadar, S. and Ganji, D.D. (2015) MHD Stagnation Flow towards a Porous Stretching Sheet with Suction or Injection and Prescribed Surface Heat Flux. Journal of the Brazilian Society of Mechanical Sciences and Engineering, 37, 837-847. http://dx.doi.org/10.1007/s40430-014-0218-z

[16] Cao, L., Si, X., Zheng, L. and Pang, H. (2015) The Analysis of the Suction/Injection on the MHD Maxwell Fluid past a Stretching Plate in the Presence of Nanoparticles by Lie Group Method. Open Physics, 13, 135-141. http://dx.doi.org/10.1515/phys-2015-0017

[17] Lin, Y., Zheng, L., Li, B. and Ma, L. (2015) A New Diffusion for Laminar Boundary Layer Flow of Power Law Fluids past a Flat Surface with Magnetic Effect and Suction or Injection. International Journal of Heat and Mass Transfer, 90, 1090-1097. http://dx.doi.org/10.1016/j.ijheatmasstransfer.2015.07.067

[18] Nadeem, S. and Hussain, S.T. (2014) Flow and Heat Transfer Analysis of Williamson Nanofluid. Applied Nanoscience, 4, 1005-1012. http://dx.doi.org/10.1007/s13204-013-0282-1

[19] Gorla, R.S.R. and Sidawi, I. (1994) Free Convection on a Vertical Stretching Surface with Suction and Blowing. Applied Scientific Research, 52, 247-257. http://dx.doi.org/10.1007/BF00853952

[20] Goyal, M. and Bhargava, R. (2014) Boundary Layer Flow and Heat Transfer of Viscoelastic Nanofluids past a Stretching Sheet with Partial Slip Conditions. Applied Nanoscience, 4, 761-767.

http://dx.doi.org/10.1007/s13204-013-0254-5 


\section{Nomenclature}

$u, v \quad$-Velocity components along $x, y$ axis.

$v \quad$-Kinematic viscosity

$\rho \quad$-Density of the fluid

$\sigma \quad$-Electrical conductivity of the fluid

$T$-Nanofluid temperature

$T_{\infty} \quad$-Ambient temperature as $y$ tends to infinity

$T_{w} \quad$-Temperature at stretching surface

C -Concentration

$C_{w}$-Concentration at stretching surface

$C_{\infty}$-Ambient concentration as $y$ tends to infinity

$C_{f} \quad$-Skin friction coefficient

$P_{r} \quad$-Prandtl number

$S_{c} \quad$-Schmidt number

$N u_{x}$-Local Nusselt number

$S h_{x}$-Local Sherwood number

$s \quad$-Suction/injection parameter

$R d$-Thermal radiation parameter

$\eta \quad$-Non-linear stretching parameter

$q_{r} \quad$-Radiative heat flux

$c_{p} \quad$-Specific heat at constant pressure

D -Mass diffusivity

$U_{w} \quad$-Surface velocity

$B_{0} \quad$-Induced magnetic field

M -Magnetic parameter

$H$-Dimensionless concentration 